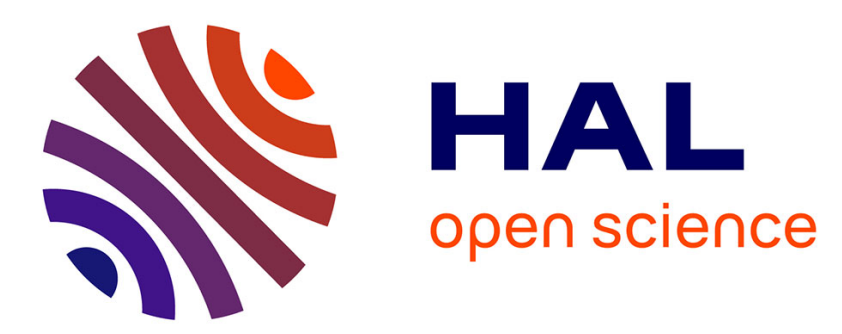

\title{
Intralaminar shear loading effects on the damage process of multiply composites at impact rates
}

\author{
M. Delaet, J. Lataillade, C. Wolff
}

\section{To cite this version:}

M. Delaet, J. Lataillade, C. Wolff. Intralaminar shear loading effects on the damage process of multiply composites at impact rates. Journal de Physique IV Proceedings, 1994, 04 (C8), pp.C8-213-C8-218. 10.1051/.jp4:1994831 . jpa-00253386

\section{HAL Id: jpa-00253386 https://hal.science/jpa-00253386}

Submitted on 1 Jan 1994

HAL is a multi-disciplinary open access archive for the deposit and dissemination of scientific research documents, whether they are published or not. The documents may come from teaching and research institutions in France or abroad, or from public or private research centers.
L'archive ouverte pluridisciplinaire HAL, est destinée au dépôt et à la diffusion de documents scientifiques de niveau recherche, publiés ou non, émanant des établissements d'enseignement et de recherche français ou étrangers, des laboratoires publics ou privés. 


\title{
Intralaminar shear loading effects on the damage process of multiply composites at impact rates
}

\author{
M. Delaet, J.L. Lataillade and C. Wolff* \\ LAMEF-ENSAM, Esplanade des Arts et Métiers, 33405 Talence cedex, France \\ * Renault S.A., Direction des Etudes Matériaux, 63 rue Galliéni, 92508 Rueil-Malmaison cedex, France
}

\begin{abstract}
Résumé : Les matériaux composites, comme matériaux constitutifs d'éléments de structures dédiés à l'absorption d'énergie lors d'un crash, sont a priori les mieux adaptés pour répondre à cette spécification de besoins. Cependant, l'absorption peut être stoppée par l'apparition de mécanismes, comme le cisaillement intralaminaire, conduisant à la ruine prématurée de la structure. Ce travail a alors pour but l'étude de l'effet de ces contraintes de cission aux interfaces fibre-matrice pour tels matériaux soumis à un impact. Deux dispositifs d'impacts ont été modifiés afin d'étudier, sous différentes vitesses de sollicitation, le comportement macroscopique des processus d'endommagement initiés au sein de stratifiés verre $\mathrm{E}$ - époxyde. Une analyse microscopique du dommage permet de déterminer la nature de l'endommagement, son mode de propagation et sa localisation.
\end{abstract}

\begin{abstract}
Composite materials, when they are used as structural elements to ensure absorption energy during impacts, can give better results than those of steel. However, their energy absorption capacities can be reduced due to some damage mechanisms, like intralaminar shear, which induce a premature failure. The aim of this study is to investigate the intralaminar shear effects at fibre-matrix interfaces when composite materials are subjected to impacts. A servo-hydraulic testing machine and a Hopkinson bars tensile apparatus were improved to investigate, by using Damage Mechanics, the shear behaviour under high strain rates of E-glass reinforced epoxy crossply laminates. A microscopical analysis of the damage phenomena allows us to know the damage initiation and propagation processes.
\end{abstract}

\section{INTRODUCTION}

For the safety of car users, vehicles have to be made with the aim to absorb, during a crash, great energy amounts resulting from deformation of the front of their structure. In this way, the passenger compartment can be protected from great deformations which could cause body damage. Some parts of a structure are therefore adapted to the energy absorbing function which arises by solid deformation. Composite materials, intended for this energy absorbing function, get absorption capacities which are better than those of metallic materials [1]. However, energy absorption mechanisms of composite structures are quite different from metallic ones and are very complex [2]. As a general rule, two main crushing mechanisms are observed when cylindrical or rectangular tubes are submitted to uniaxial compressive loading. A stable one allows large energy absorption capacities due to successive micro-cracks. However, a sudden and premature failure of the structure, without stored energy, often occurs due to the presence of an unstable brittle mechanism due to interlaminar shear, buckling or shear along fibres. Furthermore, cracking along fibres (intralaminar shear) has been identified as a mechanism of great importance which is responsible for the unstable behaviour of such structures [2].

The aim of our study is therefore to characterise the intralaminar shear damage processes within long E glass reinforced epoxy composites. In this way, an approach by means of the damage mechanics is proposed. The mechanical test are achieved by using several kinds of impact testing apparatus to investigate a large range of strain rates; these tests allow us to evaluate the high strain rate effects on the initiation and the propagation of the damage, assuming that the response of each sample is representative of the average behaviour. Finally, a microscopic analysis allows us to localise and to identify the various damage initiation and propagation processes. 


\section{UNIAXIAL TENSILE TEST ON $( \pm 45)_{\mathrm{S}}$ LAMINATES.}

$( \pm \theta)_{S}$ laminates are often tested under tension loading (Figure 1) because the fibre/matrix interphases have a great role within these particular structures. Furthermore, at an angle of 45 degrees, intralaminar shear stress and strain are optimum values with respect to transverse stress and strain [3]. PETIT [4], from the classical laminate theory, computes the intralaminar shear modulus $\mathrm{G}_{12}$ of the material by using the $( \pm 45)_{\mathrm{S}}$ laminate longitudinal modulus $\mathrm{E}_{\mathrm{XX}}$ and the longitudinal and transverse material properties.

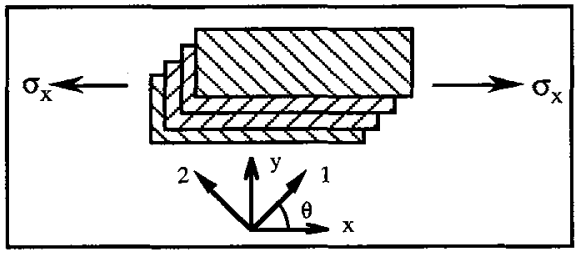

Figure 1. Uniaxial tensile test on $( \pm \theta)_{\mathrm{S}}$ crossply laminates.

$$
G_{12}=\frac{2 U_{1} E_{X X}}{8 U_{1}-E_{X X}} \text { (1) in which } U_{1}=\frac{1}{8\left(1-v_{12} v_{21}\right)}\left(E_{11}+E_{22}+2 v_{21} E_{11}\right) \text { (2) and } v_{21}=\frac{v_{12} E_{22}}{E_{11}}
$$

$E_{11}, E_{22}, v_{12}, v_{21}$ are respectively the material longitudinal and transverse moduli and the Poisson's ratios measured within an unidirectional ply.

\section{EXPERIMENTAL TECHNIQUES.}

The second step in developing the impact investigation concerns the adaptation of several high strain rate testing devices from the previous uniaxial tensile test on $( \pm 45)_{\mathrm{S}}$ crossply laminates. First, a tensile testing machine with a large inertia wheel loading (Figure 2) allows us to test composites until failure under high strain rates $\left(10^{2}\right.$ to $\left.10^{3} \mathrm{~s}^{-1}\right)$. The principle of this apparatus is based on a large inertia wheel, with a constant rotational speed ( 5 to $50 \mathrm{rad} . \mathrm{s}^{-1}$ ), which catches the head of the specimen attached to a fixed support. Samples to test are therefore submitted to linear speeds which vary between 1 to $10 \mathrm{~m} / \mathrm{s}$. Using specimens with sizes described in figure 5, strain rates induced within such samples vary from $10^{2}$ to $10^{3} \mathrm{~s}^{-}$ 1. A ZIMMER electro-optical extensometer, adjusted to the sample, give measurements of its longitudinal displacement.

To develop our study under medium strain rates $\left(10\right.$ to $\left.10^{2} \mathrm{~s}^{-1}\right)$, the same failure tests are achieved, within the range of $0.01-1 \mathrm{~m} . \mathrm{s}^{-1}$, with an INSTRON high velocity servo-hydraulic testing machine. This apparatus consists of giving a constant velocity to an hydraulic jack which tests specimens under tensile loading.

To investigate the damage phenomena induced within composite materials under high strain rates, two machines, in which it is possible to stop

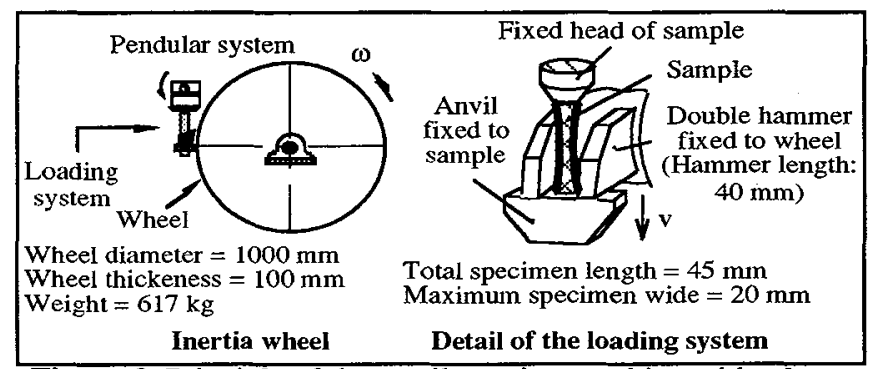

Figure 2. Principle of the tensile testing machine with a large inertia wheel loading.

the test at predetermined loading thresholds, are used. The first one is based on the use of the previous servo-hydraulic testing machine and allows us to test samples under medium strain rates $\left(10\right.$ to $\left.10^{2} \mathrm{~s}^{-1}\right)$. However, the principle of such an apparatus does not allow us to stop the hydraulic jack displacement during the test. Hence, the end of the test is governed by the failure of the specimen. Therefore, to load samples to different stress thresholds a mechanical fuse has been designed (Figure 3 ) and it is held in series with the composite sample. Failure of this fuse allows us to stop the test at chosen stress or strain levels; the composite sample is damaged but not failed. PMMA (Poly-methyl-metacrylate) has been chosen to be machined as DEN (Double Edge Notched) samples for tensile tests. The behaviour of such mechanical fuses is brittle and a small amount of energy is stored. Sizes of fuses are $150 * 30 * 8 \mathrm{~mm}^{3}$; when initial notches lengths vary from 5 to $2 \mathrm{~mm}$, the failure loads increase from 500 to $3000 \mathrm{~N}$ and are quite reproducible.

At the highest strain rates (up to $10^{3} \mathrm{~s}^{-1}$ ), we use a modified Hopkinson bar tensile apparatus. This is made up of two long cylindrical steel bars (input and output bars) and the sample is strongly held between them. A projectile, propelled by a compressed air gun along the input bar, impinges on an anvil attached to the free end of this last bar (Figure 4). A tensile longitudinal elastic wave is then created and spreads towards the sample and the output bar. Due to mechanical impedance changes between the composite sample and the steel bars, a transmission-reflection phenomenon of the incident tensile wave occurs at the input bar - sample and sample - output bar interfaces. 
Analysis of the stress and strain states versus time are obtained using the elastic one dimensional wave propagation theory. With strain gages located on each bar, the forces and displacements at the two samplebar interfaces are measured and the quasi-static loading state hypothesis within a sample allows us to compute stress and strain within it.

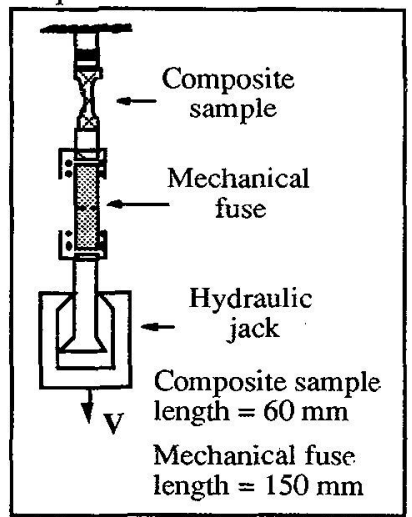

Figure 3. Schema of the servo-hydraulic testing machine with PMMA fuse.

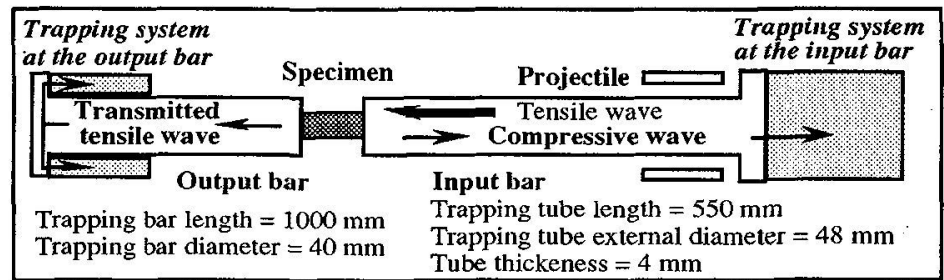

Figure 4. Schema of the Hopkinson pressure bars with trapping systems at the input and output bar free ends.

To damage samples at different stress thresholds [5], interrupted tests are achieved by using different lengths for the projectiles which are propelled at the same velocity. Indeed, the duration of the wave created within the input bar, and hence the load duration, is proportional to these projectile lengths $(T=2 \mathrm{~L} / \mathrm{c}(13)$ in which $T, \mathrm{~L}$ and $\mathrm{c}$ are respectively the wave duration, the projectile length and the wave velocity within it). However, the reflected wave within the input bar and the transmitted wave within the output bar have to be suppressed to avoid waves returning within the samples by reflection at the free end of each bar. For this purpose, a new moving bar, with the same cylindrical geometry and the same mechanical impedance, is placed in contact with the free end of the input bar (Figure 4). The reflected incident wave at the input bar/sample interface, a compressive wave, is fully transmitted into the "trapping bar" thus creating a loss of contact between the two elements. The undesirable wave is therefore trapped and the composite sample cannot be loaded a second time. In a similar manner, a steel tube which is able to slide along the output bar is located, at the beginning of each test, in contact with an anvil attached to the free end of the output bar (Figure 4). In this way, the tensile wave is transmitted from the output bar into the tube as a compressive wave. When this reflects as a tensile wave, the tube and the output bar separate and no reflected wave reaches the specimen.

\section{EXPERIMENTATION.}

The material to test is a crossply laminate constituted with long $\mathrm{E}$ glass fibres embedded in an epoxy matrix. Fibre content is $43 \%$ by volume. 12 layers are manufactured from unidirectional prepreg with the stacking sequence of plies alternately oriented, in a symmetrical manner, at 0 and 90 degrees with regard to the plate axis. Thickness of these layers is $(2.3 \pm 0.1) \mathrm{mm}$. They are then machined in the 45 degree direction with a water jet cutting system (jet diameter : 0.1 to $0.3 \mathrm{~mm}$; jet speed : $900 \mathrm{~m} / \mathrm{s}$ ) as dumbell shape specimens (Figure 5). Special care is taken to avoid free edge delaminations. The effective length and width of each sample are respectively $(12.5 \pm 0.1) \mathrm{mm}$ and $(5.7 \pm 0.1) \mathrm{mm}$. These sample sizes do not agree with any ASTM standard because none is defined where high strain rate tests are concerned. Indeed, the effective lengths of specimens must be short enough to induce within them a quasi-static loading state.

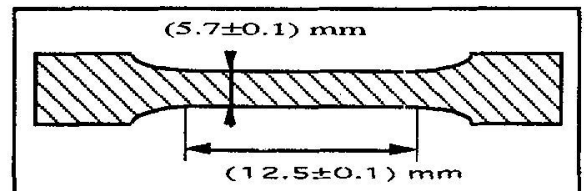

Figure 5. Dumbbell shape specimen for tensile tests.

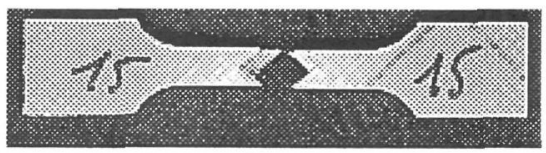

Figure 6. Broken specimen under $247 \mathrm{~s}^{-1}$ strain rate.

\subsection{Failure tests.}

The uniaxial tensile tests on $( \pm 45)_{S}$ crossply laminates achieved until failure of specimens (Figure 6 ) show that the intralaminar shear behaviour is similar whatever strain rate (Figure 7). The material response is first almost linear. Then, the slope of the curve changes ; it decreases to a constant value. So, this anelastic shear behaviour appears to be linear until the sudden failure of the specimen. At the beginning of the linear softened plateau the yield limit is defined and measured versus strain rate. The failure strength is also measured. It appears, from figure 8 , that the yield stresses and the failure strengths increase in a linear law versus the logarithm of strain rate. 


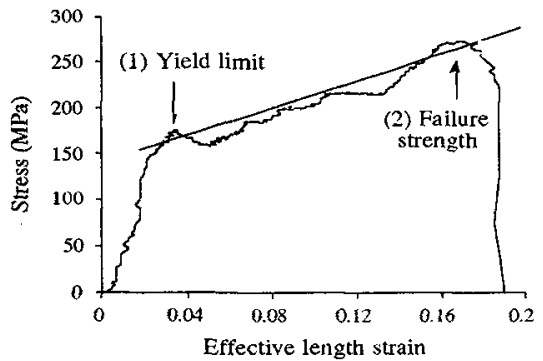

Figure 7. Behaviour curve under $415 \mathrm{~s}^{-1}$ strain rate.

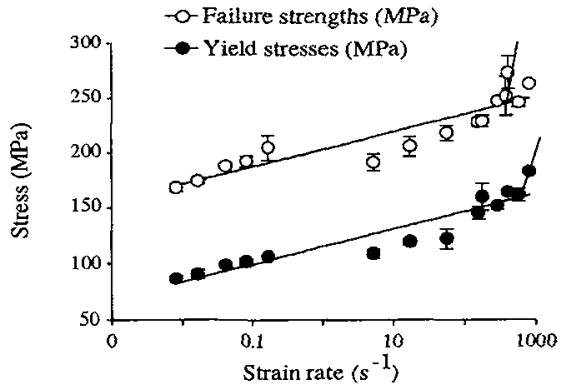

Figure 8. Yield stresses and failure strengths versus strain rates.

\subsection{Interrupted tensile tests to evaluate damage growth within composites.}

In order to investigate the high strain rate effects on the shear damage mechanisms which control the composite mechanical properties, the approach of the study by means of interrupted tensile tests is now presented. Some loading curves, for different stress thresholds and related to each testing device, are shown in figures 9 and 10.

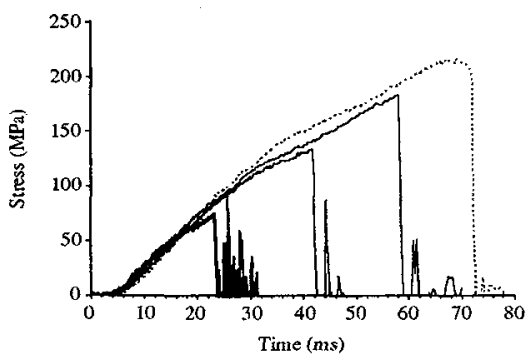

Figure 9. Interrupted tests applied to the servohydraulic testing machine $\left(\dot{\varepsilon}=4.8 \mathrm{~s}^{-1}\right)$.

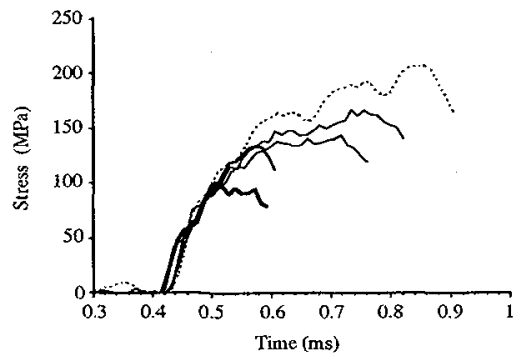

Figure 10. Interrupted tests applied to the Hopkinson bars tensile apparatus $\left(\dot{\varepsilon}=299 \mathrm{~s}^{-1}\right)$.

Residual properties of the damaged composite samples are measured by means of static tensile tests ( $\mathrm{V}$ $=10 \mathrm{~mm} / \mathrm{min}$ ). The damage level within each laminate is therefore quantified from the measurement of its static elastic longitudinal modulus, at $0.2 \%$ strain, which is chosen as a damage indicator. The static elastic longitudinal modulus of undamaged samples being used as the reference damage indicator, a damage variable $\mathrm{D}$ is defined and computed : $D=\frac{E_{0}-E_{D}}{E_{0}}$ (4) where $\mathrm{E}_{0}$ and $\mathrm{E}_{\mathrm{D}}$ are respectively the static elastic longitudinal modulus of the undamaged and the damaged specimens. This damage variable, related to the longitudinal modulus of the laminates and therefore to the material intralaminar shear modulus (see equation 1 ), is a representative value of the damage due to intralaminar shear loading.

The evolution of this damage variable $\mathrm{D}$, versus stresse within composites, is of the same shape whatever the strain rate. When it is submitted to a $80 \mathrm{~s}^{-1}$ strain rate test, the damage variable $\mathrm{D}$ evolves as shown in figure 11. It is near zero until it reaches the "damage initiation threshold". Beyond, the damage evolution law linearly increases. Rclated to the damage initiation and the damage growth within samples, two parameters are defined and measured versus strain rate. The first one is the stress at the damage initiation threshold while the other is the linear slope of the damage variable increase $(\partial D / \partial \sigma)$. This last parameter is called as the "damage rate of increase" and it is considered like a damage propagation rate indicator. From figure 12, it appears that the damage initiation threshold linearly increases versus the logarithm of strain rate. On the other hand, the damage rate of increase $(\partial D / \partial \sigma)$ decreases when the logarithm of strain rate increases (Figure 13).

\section{MICROSCOPIC ANALYSIS OF THE DAMAGE PROCESSES.}

With the aim of investigating the microscopic damage processes which initiate the degradation of the $( \pm 45)$ laminates in tensile tests, a damage analysis is made using electron scanning micrography technique. 
A manual polishing of about $(1.2 \pm 0.2) \mathrm{mm}$ in depth is achieved to one of the lateral sides (thickeness section) of the damaged specimens. The studied zone is therefore located within the effective volume of the material and allows us to identify a damage process at the fibre-matrix interfaces occuring in three stages. First, the damage initiation occurs with some fibre-matrix interfaces unsticking (Figure 14). Then, this phenomenon grows around fibres (Figure 15) until the coalescence of the microcracks from one fibre to an other one. These microcracks propagate across the entire ply (Figure 16). However, no delamination is observed during the loading stage.

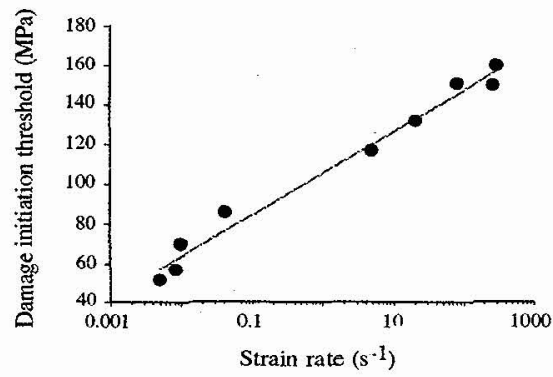

Figure 12. Damage initiation threshold versus strain rate.

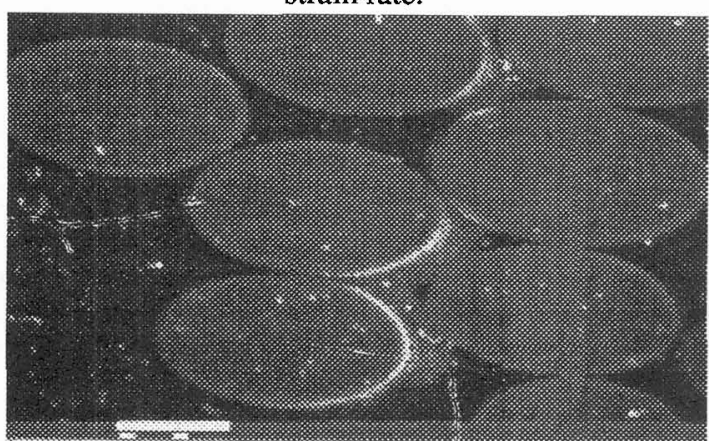

Figure 14. Damage initiation.

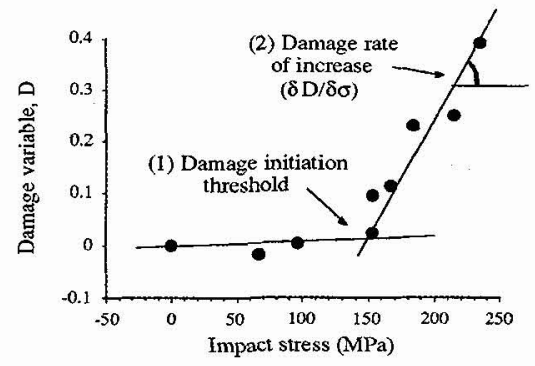

Figure 11. Damage variable D $\left(\dot{\varepsilon}=80 s^{-1}\right)$.

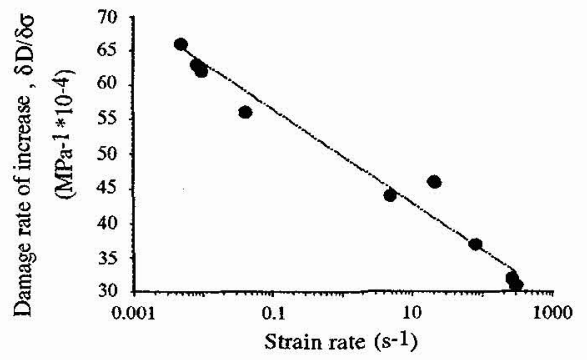

Figure 13. Damage rate of increase versus strain rate.

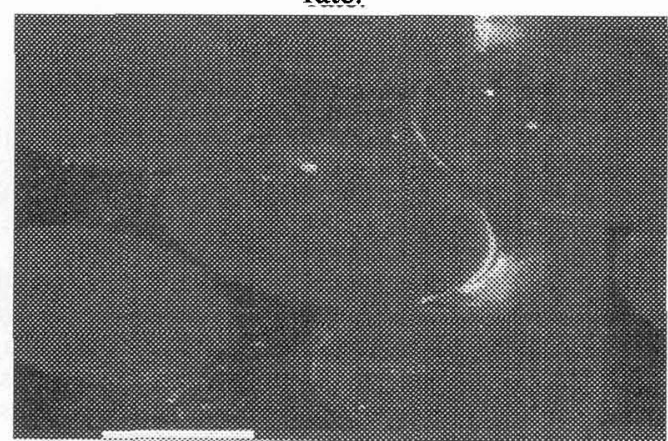

Figure 15. Damage propagation.

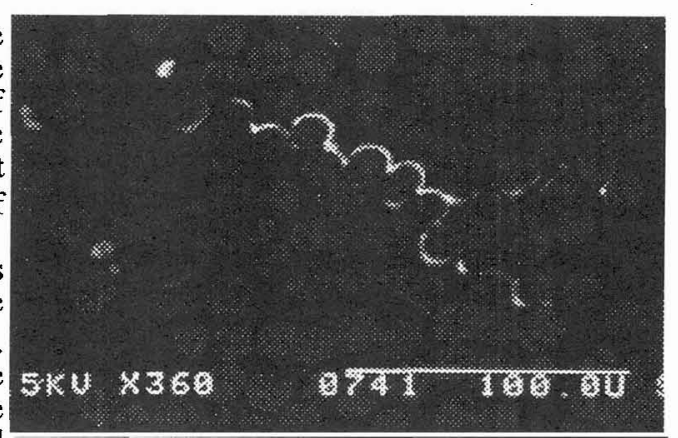

Figure 16. Coalescence of microcracks. macroscopic damage variables allows us to consider these two parameters as effective to give information about the damage level of composites submitted to an intralaminar shear loading state. Then, an average amount of the unstuck fibre - matrix interfaces which take part in an entire crack is measured for each damaged sample. This crack length indicator, plotted in figure 18 , shows that the crack growth rate decreases with a strain rate increase. This agrees with the 
previous observations according to the fact that the damage rate of increase $\partial D / \partial \sigma$ decreases with a strain rate increase.

Finally, an average crack spacing is computed from measurements within the entire polished section of the laminates. The values are plotted versus strain rate in figure 19. It appears that the average crack spacing decreases when strain rate increases. However, further microscopic analysis show that cracks are homogeneously distributed within damaged samples submitted to low strain rates. On the contrary, when subjected to high strain rate, crack spacing is short but cracks are located within groups which are heterogeneously distributed near the centre of the specimens.

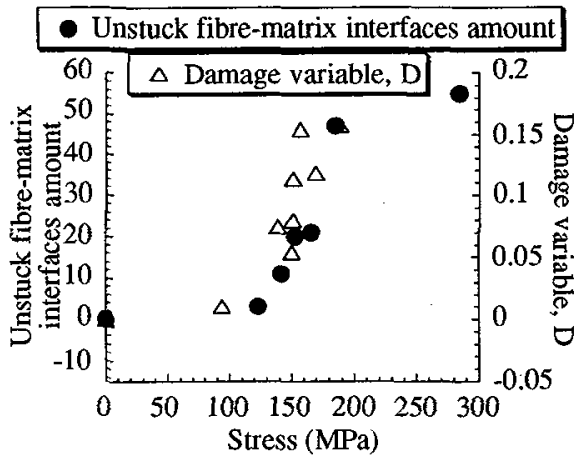

Figure 17. Damaged interface amount and macroscopic damage variable $\left(\dot{\varepsilon}=265 s^{-1}\right)$.

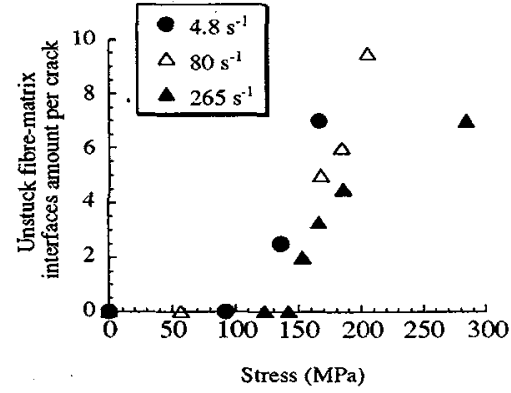

Figure 18. Damaged fibre-matrix interface amount per crack versus dynamic stresses.

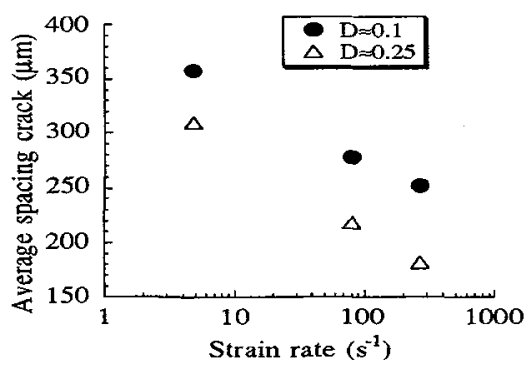

Figure 19. Average spacing crack versus strain rates.

\section{CONCLUSIONS.}

The foregoing damage study by means of interrupted loading tests appears to be reliable for investigating the progressive degradation mechanisms within composite materials under intralaminar shear loading. With this technique, we have clearly shown that intralaminar shear behaviour within fibre reinforced epoxy composites is governed by a damage growth process. Our study allows us to define some relations coupling the elastic properties of composites with their damage level. Furthermore, the use of interrupted tests to damage samples to different stress thresholds allows us to know, under high strain rates, the history of materials degradation.

The damage initiation and the damage propagation processes appear to be very sensitive to strain rate effects. In fact, it is possible to explain the modifications of the damage processes by knowing the matrix sensitivity with regard to strain rate. Hence, temperature changes are assumed to act on the damage phenomena which induce the composites failure. It is therefore necessary to investigate the influence of a temperature field on the damage processes induced within composites.

\section{ACKNOWLEDGEMENTS}

The authors are indebted to the Régie RENAULT and the "Association Nationale de la Recherche Technique" for supporting this work.

\section{REFERENCES}

[1] Zeitouni R., "Contribution à l'étude de l'absorption d'énergie par mécanisme de déchirure des matériaux composites", Thèse Doctorat Ecole Centrale de Nantes (February 1993) N ED82-16.

[2] Wolff C., "Approche thermomécanique et modélisation du comportement en absorption d'énergie de tubes composites", Thèse de Doctorat Ecole Nationale Supérieure des Mines de Paris (June 1991).

[3] Charentenay F. X. and Kamimura K., Annales des Composites 2 (1982) 3-32.

[4] Petit P. H., Composite Materials : Testing and Design, ASTM STP 460 (1969) 83-93.

[5] Lataillade J.L., Delaet M., Collombet F., ICCM9, Volume 5, Madrid Juillet 1993, pp. 358-365. 